$\begin{array}{ll}\text { REVISTA } & \text { NARRATINS } \\ \text { DA } \\ \text { FUNDARTE }\end{array}$

\title{
VIDA OU MORTE PARA O TEATRO INFANTIL? CONTRAPONTOS
}

Marina Marcondes Machado

DOI: $10.19179 / 2319-0868.783$ 


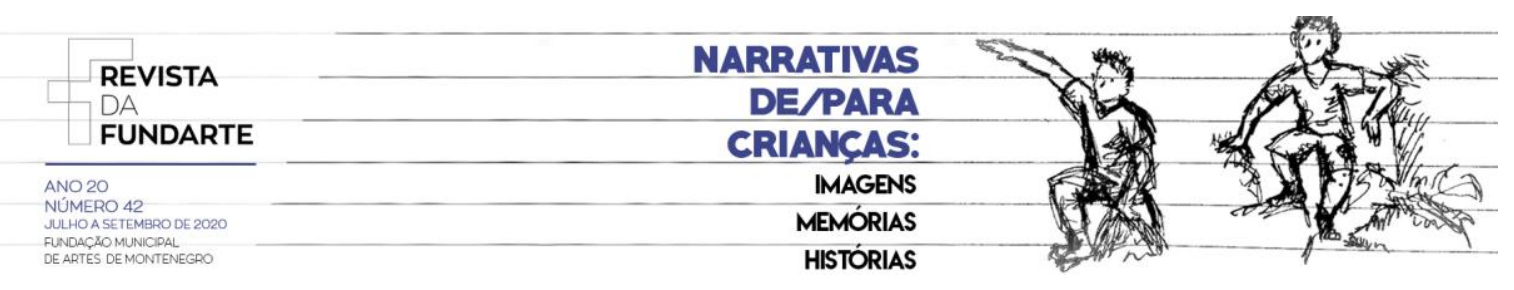

\title{
VIDA OU MORTE PARA O TEATRO INFANTIL? CONTRAPONTOS
}

Marina Marcondes Machado ${ }^{1}$

Resumo: Neste texto me pergunto como e por que produtores adultos de culturas da infância seguem fazendo um teatro infantil congelado no tempo, tal qual a situação da personagem Bela Adormecida. $\mathrm{O}$ que despertaria a comunidade adulta para outros modos de fazer teatro, incluindo 0 teatro feito por crianças, rico em expressividade e conversa? Haveria chance de existir, hoje, um "teatro para todas as idades"? A resposta é delicada e complexa, pelo momento mundial: estamos política e culturalmente definidos por dicotomias que revelam posições inconciliáveis, seja acerca da produção cultural para crianças, seja acerca do papel dos adultos diante delas.

Palavras-chave: Culturas da infância; Teatro infantil; Teatro para todas as idades.

\section{DEATH OR LIFE TO CHILDREN'S THEATER? COUNTERPOINTS}

\begin{abstract}
In this text I will ask how and why adults that produce culture continue to make a frozen in time theater, imitating the character Sleeping Beauty's circumstances. What kind of awakening do the adults need so as to be aware of other different plays, accepting those created by children, rich in expressiveness and conversation? Is there any chance for a "theater for all ages" to exist nowadays? The answer is delicate and complex, because the worldwide moment: we seem to be cultural and politically defined by dichotomies, revealing opposed positions - about childhood cultures as well as the adult's role in the face of it.
\end{abstract}

Keywords: Childhood cultures; Children's theater; Theater for all ages.

\section{VIE OU MORT POUR LE THÉÂTRE POUR ENFANTS? CONTREPOINTS}

Résumé:Dans ce texte, je me demande comment et pourquoi les producteurs adultes des cultures de l'enfance continuent de faire un théâtre pour enfants figé dans le temps, tout comme la situation du personnage de la Belle au bois dormant. Qu'est-ce qui éveillerait la communauté adulte à d'autres façons de faire du théâtre, y compris le théâtre fait par des enfants, riche en expressivité et en conversation? Y aurait-il une chance qu'il y ait, aujourd'hui, un "théâtre pour tous les âges"? La réponse est délicate et complexe, à cause du moment global: nous sommes politiquement et culturellement définis par des dichotomies qui révèlent des positions inconciliables, que ce soit sur la production culturelle pour les enfants ou sur le rôle des adultes vis-à-vis d'eux.

Mots-clés: Cultures de l'enfance; Théâtre pour enfants; Théâtre pour tous les âges.

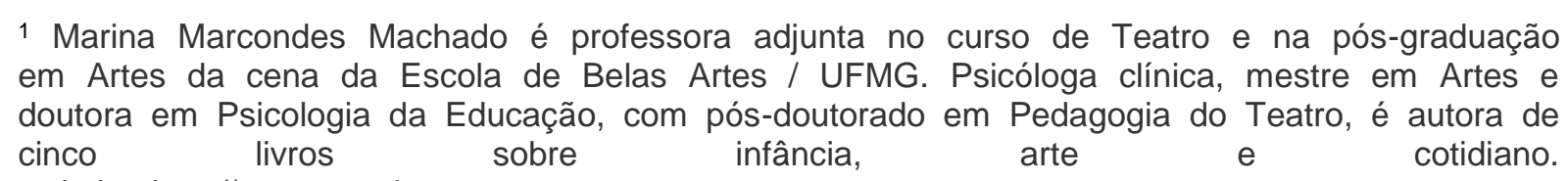
website: http://www.agachamento.com

MACHADO, Marina Marcondes. Vida ou morte para o teatro infantil? Contrapontos. Revista da FUNDARTE. Montenegro, p.01-20, ano 20, № 42, julho/setembro de 2020.

Disponível em: http://.seer.fundarte.rs.gov.br/index.php/RevistadaFundarte/index> 30 de setembro de 2020 


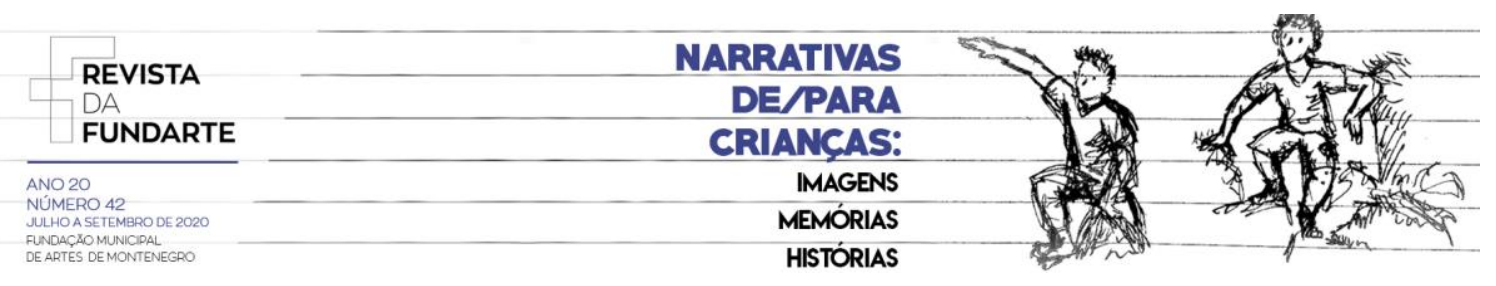

\section{Para introduzir: Infâncias plurais}

Infância burguesa, infância proletária

Aproximadamente cem anos atrás Walter Benjamin publicou um ensaio curto tematizando o teatro proletário com crianças. Um texto a ser lido hoje com muito cuidado, pois, se usarmos as lentes contemporâneas, podemos nos espantar muito com o linguajar: a vanguarda da época se debruçava sobre uma pedagogia comunista; também para não causar espanto, nem julgamento de valor, é preciso compreender como mudou o modo de produção, como mudou a infância, e como mudou o teatro - e também como não mudou o teatro infantil tradicional (dito "burguês" por Benjamin, em sua reflexão). O ensaio discute um "Programa de um teatro infantil proletário" (título do texto) e sua publicação aconteceu em 1928.

Pretendo localizar o pensamento de Benjamin e Asja Lācis, amiga de Benjamin para a qual ele escreveu o texto - explicitação ou teorização de uma prática concretizada por ela. Para perceber a riqueza da proposta, devemos lembrar que, no final do século $X I X$, as crianças proletárias não eram apenas e simplesmente os filhos dos operários: as crianças trabalhavam na indústria. Eram responsáveis, por exemplo, pela limpeza das máquinas em intervalos da produção, pois seus corpos eram pequenos o suficiente para se embrenharem nas engrenagens. Assim aconteceram inúmeros acidentes com crianças, incluindo mortes e severas mutilações, "naturalizadas", ou seja, não existia regulamentação do trabalho infantil. O texto de Benjamin tematiza a criança burguesa e a visão adulta, também burguesa, de uma infância escolarizada e psicologizante - lógica na qual os adultos sabem o que é bom para a criança - para contrapor à criança proletária, cuja vida se dá em "um contexto, de um terreno objetivo no qual se é educado. Não precisa, como a burguesia, de uma ideia para a qual se é educado" (BENJAMIN, 1984, p.84). No teatro proletário, "toda ação e gesto infantil transformase em sinal" (idem, p.85). Lācis criou e trabalhou o "teatro infantil proletário" com crianças órfãs e crianças de rua, e foi muito provavelmente pioneira em um tipo de teatro: feito com crianças e para crianças assistirem. 


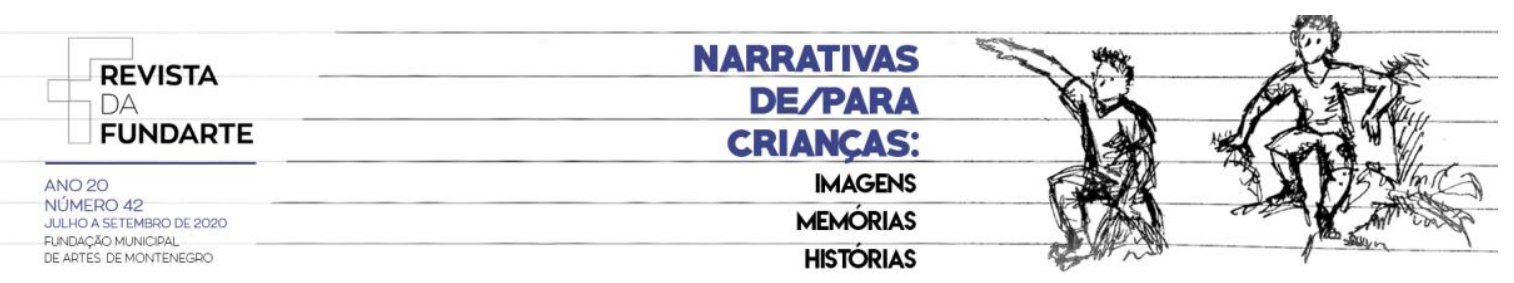

O texto sobre o teatro infantil proletário encontra-se em um livro (póstumo) que reúne reflexões do filósofo sobre a criança, o brinquedo e a educação, e que no Brasil foi primeiramente traduzido e editado pela Summus Editorial, na década de 1980; mais tarde, nos anos 2000, o mesmo conjunto de textos foi traduzido e editado pela Editora 34 (ambas editoras de São Paulo). Reler o ensaio para discuti-lo aqui me levou a pesquisar com maior profundidade o que era o "teatro infantil proletário" e assim descobri quem foi Asja Lācis; tratava-se de uma iniciativa dela - mulher, atriz, diretora de teatro e ativista, amiga íntima de Benjamin, amiga também de Brecht e de inúmeros outros intelectuais de esquerda na Europa - a iniciativa: fazer teatro com crianças desassistidas.

Uma das características mais interessantes proposta no programa do "teatro infantil proletário" é o fato de que

[...] as encenações desse teatro não são, como as do grande teatro da burguesia, a verdadeira meta do intenso trabalho coletivo desempenhado nos clubes infantis. Aqui as apresentações acontecem de passagem, por descuido poderíamos dizer, quase como uma travessura das crianças, que interrompem dessa maneira o estudo 0 qual, por princípio, jamais é concluído. (BENJAMIN, 1984, pg.85).

Também o papel do diretor é diverso: "[...] O diretor não dá muito valor a essa conclusão. Importa-Ihe antes as tensões que se resolvem em tais apresentações. As tensões do trabalho coletivo são os verdadeiros educadores" (BENJAMIN, 1984, pg.85).

Benjamin esclarece que as crianças, em tal teatro, são uma coletividade, tal qual "as assembleias populares, o exército, a fábrica". Essencialmente, o educador é um observador; e os procedimentos se dão em torno da improvisação:

É tarefa do diretor libertar o gesto infantil do perigoso reino mágico da mera
fantasia e conduzi-los à sua execução nos conteúdos. Isso acontece nas
diferentes sessões. [...] o essencial é o gesto. [...] Inervação criadora em
correspondência precisa com a receptiva: eis todo o gesto infantil. O
desenvolvimento desse gesto infantil até as diferentes formas de expressão,
enquanto preparação de requisitos, pintura, recitação, música, dança,
improvisação compete às diferentes sessões. Em todas elas a improvisação
permanece como central; pois, em última instância, a apresentação é apenas
a síntese improvisada de todas. A improvisação predomina; ela é a
constituição em que emergem os sinais, os gestos sinalizadores. E 


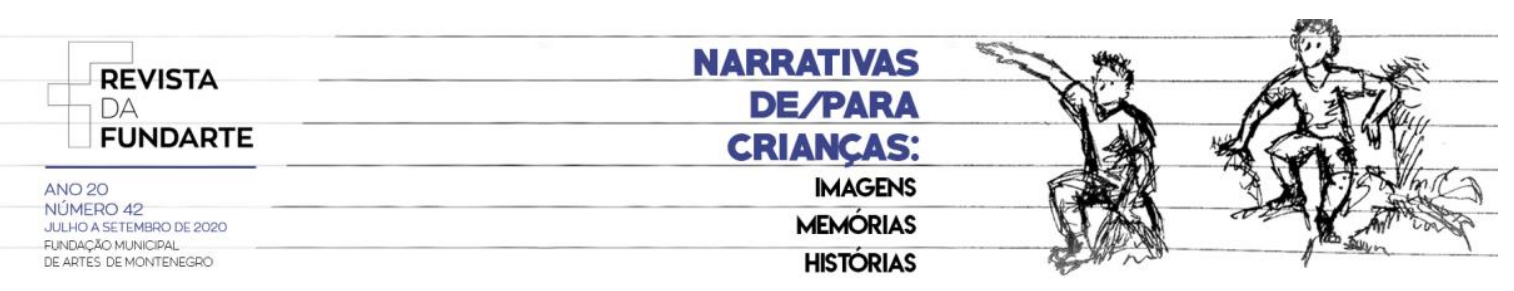

encenação ou teatro deve, justamente por isso, ser a síntese desses gestos, pois manifesta-se de maneira inesperada e apenas uma única vez, mostrando-se portanto como o autêntico espaço do gesto infantil. (...) Todo desempenho infantil orienta-se não pela "eternidade" dos produtos, mas sim pelo "instante" do gesto. O teatro, enquanto arte efêmera, é infantil. (BENJAMIN, 1984, pg. 86).

Outra afirmação que positiva o valor formativo do teatro é Benjamin dizer que "a encenação contrapõe-se ao treinamento pedagógico como libertação radical do jogo, processo que o adulto pode tão-somente observar" (1984, p.87). Jogo, gesto, observação, improvisação: elementos que cem anos atrás não eram pensados pelos produtores adultos de teatro voltado para o público infantil, não era uma discursividade própria da encenação para crianças: podemos afirmar que Lācis estava anos luz adiante de seu tempo.

Em escritos pessoais, Asja Lācis (1891-1979) explicita sua metodologia e o uso criativo que as crianças fazem da ação teatral. Encontrei, em minha pesquisa recente sobre sua vida e obra, um arquivo interessantíssimo que relata, por ela mesma, o que foi a experiência ( $L \bar{A} C I S, 2014)$. É um texto em inglês e vou me permitir "traduções livres", ao longo de minha descrição de suas ideias. A experiência deu-se em Orel. Lācis narra no referido texto que em 1918 foi a essa cidade na Rússia e percebeu gangues de crianças abandonadas nas ruas (era o período pós-primeira guerra mundial). O governo tentava alocar essas crianças em institutos educacionais, mas elas constantemente fugiam. Haviam também os órfãos de guerra, que apesar de terem um teto, comida e roupa fornecida pelo governo, pareciam-se com pessoas velhas, tristes e cansadas ("they looked like old people, with sad, tired eyes" no original). Crianças sem infância, em suas palavras; Lācis diz que não havia como ficar indiferente diante daquela situação. Escreve ela: "eu sabia do grande poder de fazer teatro e o que isso poderia fazer por aquelas crianças" (LĀCIS, 2017) (tradução nossa).

${ }^{22}$ No original: "I knew how great power of making theater was and what it might do for these children" (LĀCIS, 2017).

MACHADO, Marina Marcondes. Vida ou morte para o teatro infantil? Contrapontos. Revista da FUNDARTE. Montenegro, p.01-20, ano 20, № 42, julho/setembro de 2020.

Disponível em: http://.seer.fundarte.rs.gov.br/index.php/RevistadaFundarte/index> 30 de setembro de 2020 


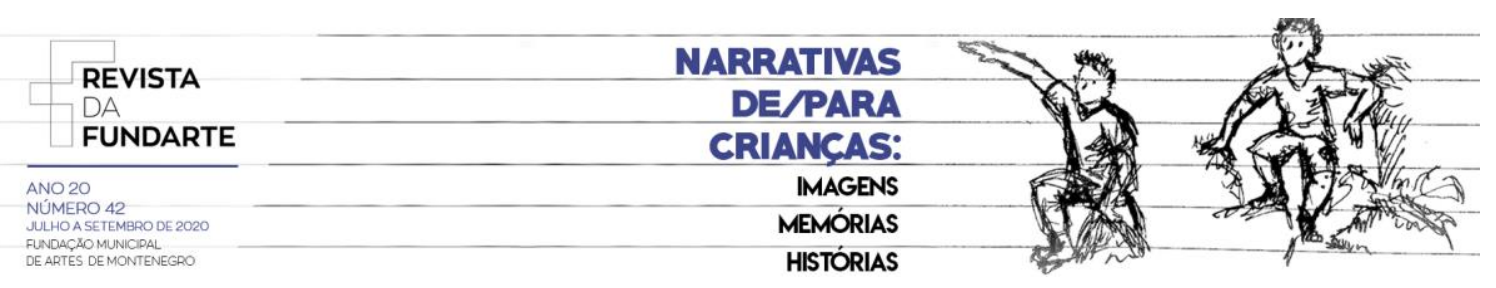

Infância positivista, infância corporativa

Agora proponho ao leitor uma breve visita a outra noção de infância daremos um salto para a "infância corporativa" (Steinberg e Kincheloe, 2001; Steinberg, 2014) - para pensar a proposta do teatro infantil como parte da indústria cultural, produzida por adultos, de modo que mais tarde poderei discutir o teatro à luz de meus estudos sobre a fenomenologia da criança e a performatividade cotidiana nos mundos de vida infantis. Minha hipótese reside na possibilidade (ou não) da existência, no século XXI, de um teatro para todas as idades.

Gostaria de reatualizar as noções teatrais do texto de Benjamin - e da prática de Lācis - em sintonia com o que Shirley Steinberg chama por pedagogia cultural. Nossa conversa se fortalecerá com a aproximação da noção de infância construída pela pesquisadora que, desde o final do século XX, desenha junto a colaboradores, algo que denominaram por kinderculture corporativa, ou, tal como traduzido para o português, a infância corporativa. Para compreender com densidade o que acontece nos mundos de vida infantis do século XXI, há que pensar de modo crítico, aproximando-nos de novos paradigmas.

Em 2001 foi publicado no Brasil o livro Cultura infantil / A construção corporativa da infância. Foi originalmente publicado nos Estados Unidos em 1997 e é uma coletânea que tematiza estudos culturais acerca da infância, apresentando um texto introdutório de Shirley Steinberg e seu esposo, hoje falecido, Joe Kincheloe. Penso que, no Brasil, foi dada pouca atenção a esse livro, talvez pelo seu foco na cultura popular norte-americana - e pelo seu tom, por vezes beirando o panfletário. Mas gosto muito de seus princípios: vivemos uma "nova era na infância" na qual, aquém e além da pedagogia escolar, surgiu, segundo Steinberg, de 1950 para cá, uma pedagogia cultural forte e poderosa na "América corporativa", capaz de revolucionar a infância:

Substituindo as tradicionais palestras e deveres nas salas de aula por bonecos com uma história, reinos mágicos, fantasias animadas, vídeos interativos, realidades virtuais, heróis de TV kickboxers, livros de terror que arrepiam a espinha e uma gama completa de formas de diversão produzidas ostensivamente por adultos mas avidamente consumidas por crianças, a 


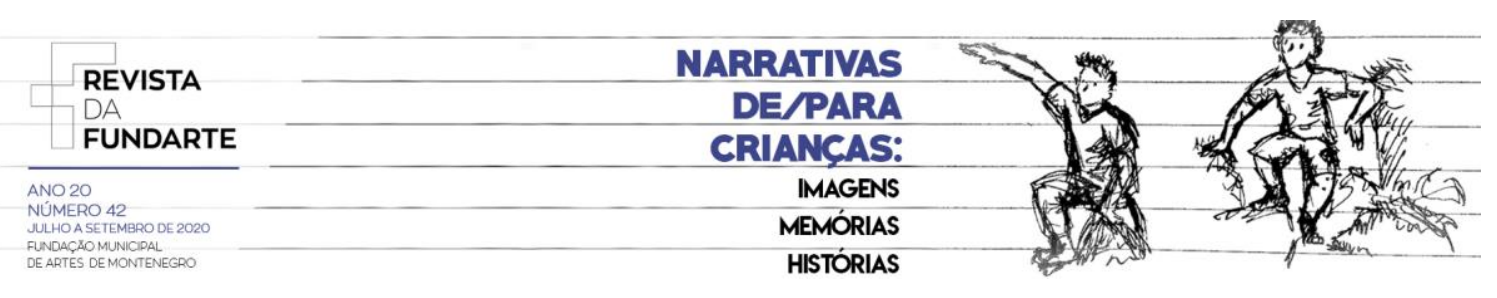

América corporativa revolucionou a infância. (STEINBERG;KINCHELOE, 2001, p.15).

Segundo Steinberg e Kincheloe, ao usar "fantasia e desejo" (2001, p.15), mesclando "ideologias de negócios e valores de livre mercado" (2001, p.15), surge "um currículo corporativo" de forte influência e de grande capacidade para oprimir e dominar as consciências infantis. É preciso, portanto, que sejam "(...) criadas estratégias de resistência que entendam o relacionamento entre pedagogia, produção de conhecimento, formação de identidade e desejo" (2001, p.15). Os efeitos políticos e sociais de um "currículo corporativo" cuja noção de infância por vezes naturaliza práticas discursivas e dinâmicas comerciais de padrões de consumo, devem ser estudados com muito cuidado, atenção e por meio de procedimentos advindos dos estudos culturais: há que "examinar a diversidade de práticas e expressões de comunicação, institucionais e artísticas de uma sociedade" (Steinberg e Kincheloe, 2001, p.17).

Em artigo mais recente, Shirley Steinberg (2014) discute a "infância corporativa" em claro contraste com o que ela descreve como a "infância positivista".

Importante destacar que, para Steinberg, a criança do século XXI não retornará ao mítico jardim secreto da inocência... ou seja, diante do bombardeamento de informações (que gerou uma vertigem social - a social vertigo, no original em inglês), não haveria outra saída senão adicionar ao currículo escolar tradicional a cultura popular e as habilidades necessárias para que crianças e jovens possam negociar suas próprias identidades, valores, e bem-estar diante de uma energia transbordante advinda da hiper-realidade(STEINBERG, 2014, p.52). Assim, o papel do adulto será fomentar situações de atitude crítica e ações cívicas. Surgem na contemporaneidade assuntos complexos, pedagógica e ideologicamente, que demandam habilidades de questionamento, análise, interpretação e doação de significatividade; Steinberg (2014) destaca que, em uma posição política à direita, seriam assuntos jamais pensados, pois o educador positivista e desenvolvimentista considera que as crianças não possuem maturidade para o pensamento crítico. Assim, em seu pensamento atual, Steinberg (2014) advoga que crianças podem - e 


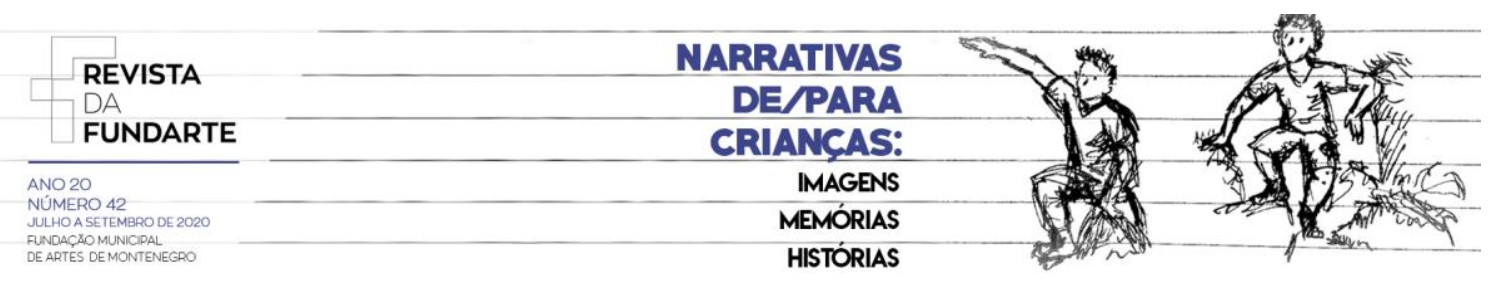

devem - ser preparadas para cooperar, doar sentido e participar do mundo adulto saturado de informações. Trata-se de uma posição que propõe gradual empoderamento das crianças, muito diversa daquela tradição que preserva a infância em seu "mundo", acreditando que as crianças devam ser protegidas e cuja relação com a indústria cultural seria de usufruto, diversão e entretenimento.

\section{Infância desenvolvimentista, infância performativa}

Agora revelo ao leitor minha contribuição própria para o debate da pluralidade das infâncias: a formulação de uma noção fenomenológica, cujo ponto de partida foram observações de crianças na cidade de São Paulo e leituras de parte das obras de Maurice Merleau-Ponty (2006) e Winnicott (1990), noção que denominei "a criança performer" e cujo desenho iniciei em minha pesquisa de pós-doutorado em $2009^{3}$.

A partir de uma imersão para estudo e compreensão de observações de crianças pequenas em situação de espera, percebi, com nitidez, as relações de poder entre adultos e crianças; grosso modo, os adultos precisavam, acreditando ser esse seu papel como cuidador, controlar os movimentos e corporalidades infantis nos locais públicos, onde esperavam pelo ônibus, pelo avião, pela saída da perua escolar, etc... Enquanto que as crianças, quanto menor fossem suas idades, mais viviam o momento e a experiência do aqui-agora. A apreensão da temporalidade era diversa, bem como a abertura para a mundaneidade. Nessa dinâmica relacional, cada passo autônomo da criança, cada gesto e palavra, pareceram-me atos performativos: de si, com o outro, no mundo.

Assim, foi a cotidianeidade de crianças na cidade de São Paulo que possibilitou esboçar a noção de criança performer. Noção correlata à de "ator social" protagonista, a partir dela pensei a performatividade própria da criança e as

\footnotetext{
${ }^{3}$ Bolsista FAPESP sob supervisão de Maria Lucia Pupo na ECA-USP, no campo da Pedagogia do Teatro. São os resultados publicados da minha pesquisa de pós-doutorado: MACHADO, M. M. A criança é performer. Educação \& Realidade. 35(2), 115-137. maio/ago 2010 e "A sutil diferença"uma das dramaturgias do livro Fim do infante / Três processos dramatúrgicos (Rio de Janeiro: Editora Circuito, 2018).
} 


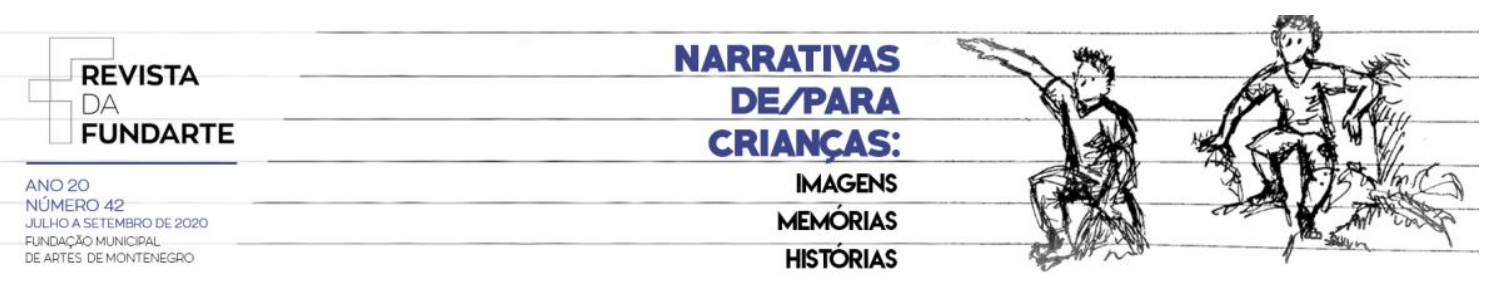

possibilidades de habitar o espaço corpo próprio, mesmo (e talvez especialmente quando) contrariando o adulto que a acompanha... Hoje, o texto produzido naquele momento (MACHADO, 2010) repercute com vigor junto a pesquisadores no campo das artes, muito especialmente nas artes da cena.

Nos últimos dez anos, tenho me ocupado especialmente com os desdobramentos da noção de criança performer no ensino de arte para crianças e jovens. Analogamente às preocupações de Shirley Steinberg (2014) com o currículo dentro e fora das escolas, estive debruçada sobre uma perspectiva na qual arte não será naturalizada em sua definição como "linguagem": em minha pesquisa, arte é âmbito ${ }^{4}$, um lugar da existência humana (desde quando bebês). Trata-se de uma perspectiva artístico-existencial. Haveriam modos de habitar o território do teatro, da dança, das artes visuais e da música como "âmbitos artístico-existenciais": teatralidade, corporalidade, espacialidade e musicalidade são palavras-chave de minha propositiva. Os modos de habitar os âmbitos artístico-existenciais partem de construções sociais e relacionais, e dependem diretamente de viver a ambiência, a criação e a performatividade do convívio junto aos adultos educadores (pais, professores, tutores, cuidadores) e junto aos seus pares também.

Trabalhar como ponto de partida uma discursividade acerca do ensino de arte me pareceu um bom começo rumo ao protagonismo infantil e a aceitação da criança performer no campo de conhecimento das artes, longe dos estereótipos das crianças mini-prodígios e da lucrativa indústria cultural; rever o que pode ser 0 ensino de arte na perspectiva de uma "abordagem espiral5" é um mote importante de meu pensamento e prática docente. Depois de cerca de 16 anos ensinando arte na Escola Municipal de Iniciação Artística de São Paulo (EMIA-SP), migrei para Belo Horizonte em 2012 e trabalho, desde então, como docente na Licenciatura em

\footnotetext{
${ }^{4}$ Definir arte como âmbito, como um lugar, um território, um híbrido entre cultura compartilhada e espaço potencial, entre espaço corpo próprio e espaço vivido, leva o campo de conhecimento artístico para uma direção das mais instigantes, o que penso ser a minha contribuição original para pensar arte, infância e currículo.

${ }^{5}$ A noção de "abordagem espiral" para o ensino de arte é desdobramento de meus estudos acerca da performatividade infantil. Para saber mais indico meu artigo "Fazer surgir antiestruturas: abordagem espiral para pensar um currículo em arte"(Revista E-curriculum. V.8, n.1, 2012).
} 


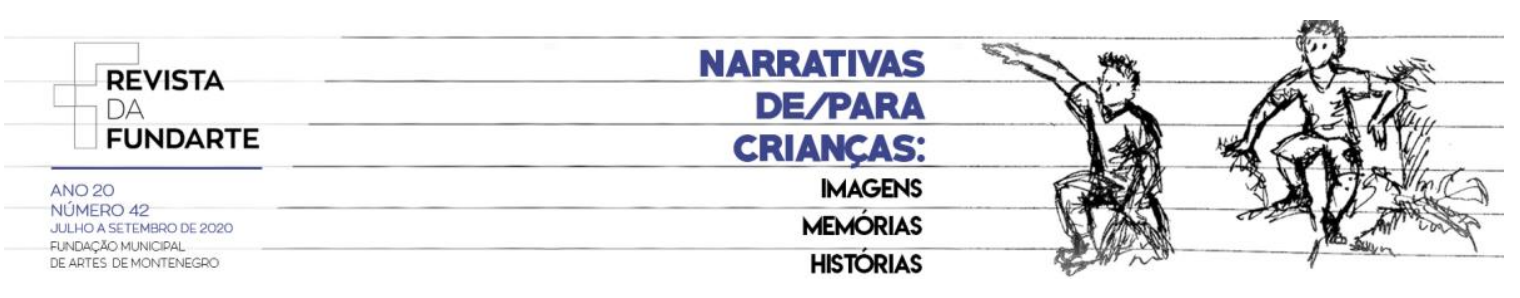

Teatro da UFMG. Em um ensaio escrito para o dossiê Performance e Escola (Cadernos Cedes, 2017), defini o campo artístico da seguinte maneira:

[...] meu campo de trabalho, o território artístico: inicio com o risco de um caminho existencial e relacional traçado de tal maneira que arte não poderá ser sinônimo de "projeto social", benevolência ou adestramento. Arte é território potente de habitarmos e espaço corpo próprio e coabitarmos o espaço mundo compartilhado. Arte é uma possibilidade relacional que espacializa imaginações. Arte é criação de muitos e muitos mundos: possíveis e incompossíveis. Arte não é maneira de "tirar o menino da rua", "tirar o menino das drogas": arte é algo que pode estar na intensa experiência da rua e que dialoga, indubitavelmente, com o recorrente desejo humano de drogar-se, anestesiar-se, jogar fora o alimento. (MACHADO, 2017, p.67).

Acredito que meu trabalho hoje quer aproximar-se e sintonizar com o que Shirley Steinberg (2014) denomina por "pedagogia cultural", havendo percepção crítica no fato de que a cada concepção de infância, surge um modo de fazer e propor o ensino de arte, bem como a produção de teatro para e com crianças.

\section{Crianças que "cantam, dançam e representam" no século XXI}

Hoje parece óbvio que não faça mais o mesmo sentido como fez para Benjamin a polarização entre a arte burguesa e a arte proletária. Deveríamos, agora, adentrar, trabalhar e estudar o terreno da cultura de massas, sintonizando naquilo que circula por entre milhões e milhões de pessoas - especialmente com o advento da internet - e que atinge culturalmente crianças do mundo todo. As culturas das infâncias e juventudes habitam, cotidianamente, os territórios virtuais, híbridos e dos multimeios.

Há uma tendência econômica de universalização de produções culturais de adultos para o consumo infanto-juvenil (que depende do engajamento dos adultos que trabalham e compram os ingressos, os objetos, os brindes) como vemos, por exemplo, em musicais produzidos ao redor do mundo, elenco local e "qualidade total" checada, vigiada, modelada pela indústria cultural da Disney em seus super espetáculos musicais, remontados na lógica de verdadeiros franchisings fora dos 


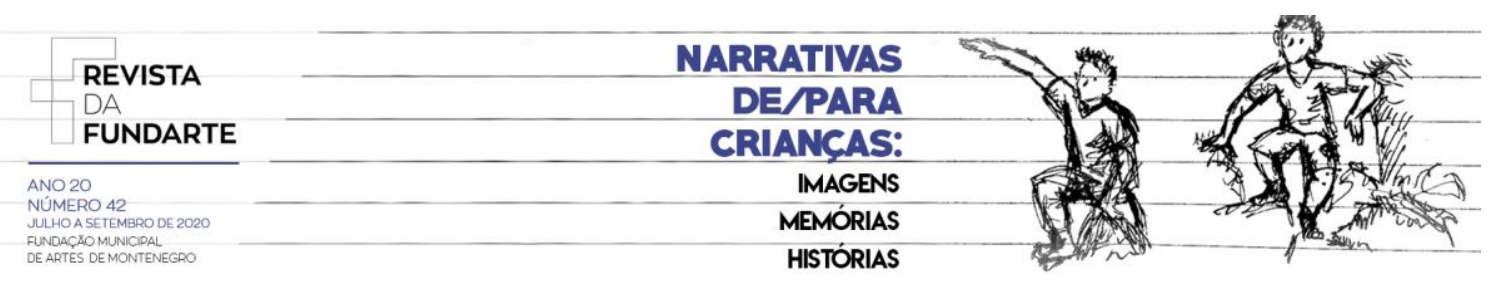

Estados Unidos ${ }^{6}$. É próprio do nosso tempo o consumo de produções adultas criadas para as crianças (e segmentos, dizem os marqueteiros "especialistas"), e a sedução dos pais que são os adultos que pagarão os ingressos, e que desejarão estar junto, "no mundo da criança" (sic). Já com menor valor econômico mas, por vezes, com imensa visibilidade estão postas criações das crianças mesmas: não apenas aquelas ligadas às escolas e a projetos sociais que ensinam arte, mas especialmente as iniciativas individuais e/ou familiares que a internet possibilitou, por meio da popularização e facilidade (seja da feitura como da postagem) de vídeos, mantidos nos canais de Youtube. Hoje há milhares de crianças respondendo, quando perguntadas sobre suas futuras profissões, que querem ser "influenciadoras digitais". A indústria cultural produzida para crianças e veiculada no YouTube atingiu, no início de 2019, a marca de 16 milhões de vídeos! E junto com ela surgiu a polêmica político-social adulta, acerca das crianças youtubers, uma vez que os canais, cujos acessos se multiplicam, ganharam contratos e anunciantes.

Enfim, crianças no mundo todo (ainda) trabalham! Algumas em trabalhos de aparência charmosa (atores, jogadores de futebol, modelos), outras, em funções subumanas (trabalho escravo, trabalho na prostituição, trabalho no tráfico de drogas). A divisão de classes permanece, com outras nomeações; embora os adultos e suas políticas públicas tenham discutido, escrito e promulgado a Declaração Universal dos Direitos das Crianças nos anos de 1950 - e no Brasil, o Estatuto da Criança e do Adolescente, que completará 30 anos em 2020 - e o mundo do adulto legalista tenha formulado a doxa do politicamente correto.

Minha proposta é a de que as crianças possam construir algo autoral na dramaturgia vivida cotidianamente: advogo, sim, as crianças como protagonistas, no entanto em uma posição como plateia pensante e pulsante, pessoas que têm algo a dizer sobre o que veem e vivem - e dizem. E que subam no palco, e desçam do palco, tornando-se capazes de dramaturgias e performances: não pelo cachê, mas

\footnotetext{
${ }^{6}$ Escolho comentar os musicais por estar tematizando especialmente o teatro, mas sabemos quão potente é a indústria cinematográfica de filmes e animação digital, histórias de super heróis e seus produtos correlatos; assim talvez o cinema fosse o exemplo mais prototípico. Além da indústria de jogos eletrônicos, é claro.
} 


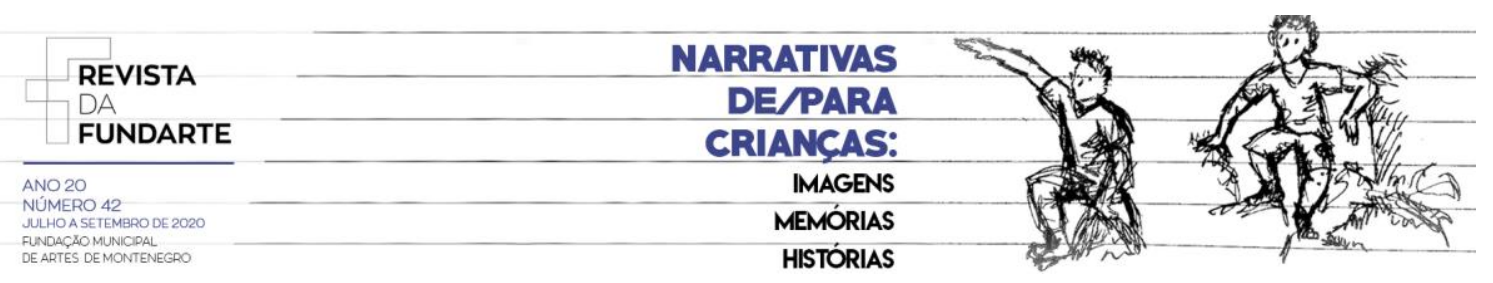

pelo ato performativo e sua potência de expressividade; pela possibilidade da presença; e por meio do desejo e do convite de dizer algo a alguém. É sobre ser escutado. É sobre uma atitude adulta na relação com a criança, com a criança performer. Esse modo de olhar para a arte a leva muito próxima da vida, e prescinde do teatro formal e sua estrutura palco-plateia.

O foco no dinheiro e na possibilidade de uma criança, com seu trabalho artístico, ser provedora da família... é algo no mínimo controverso, do ponto de vista legal e ético. Embora tão recorrente.

Em um caminho rumo a culturas compartilhadas, poderíamos pensar o fazer artístico - e especialmente o fazer teatral - de maneira menos cindida tal como vemos entre adultos que produzem arte para crianças e crianças que fazem arte?

Meu pensamento sobre arte-e-vida sintoniza com o que Jorge Dubatti (2012) define como convívio: o teatro, em sua concepção, é arte convivial por excelência. As crianças poderiam habitar e viver seus mundos de vida com menos estresse e não pautadas pelo dinheiro: residiria, neste modus operandi, o direito da criança a ser o que se é; haveria menos visibilidade, menos compartilhamentos e visualizações, mais intimidade para expressividades efêmeras. Sem foco no possível lucro e na profissionalização precoce dos "dons" ou "talentos" (para a comunicação, para a atuação, para a música, etc), as crianças talvez gerassem a antiestrutura sintonizando com as teorias da performance e antropologia, a partir das ideias de Sutton-Smith, Arnold Van Gennep e Victor Turner:

A estrutura normativa representa o equilíbrio de trabalhar; a "antiestrutura" representa o sistema latente de alternativas potenciais das quais irão surgir inovações (...). Poderíamos, mais corretamente, chamar esse segundo sistema de protocultural porque ele é o precursor das formas normativas inovadoras. É a fonte da nova cultura. (Sutton-Smith apud Carlson, 2010, p.33).

As antiestruturas são possíveis em situações liminares e liminóides, tal qual "cenários nos quais nossos modelos, símbolos, paradigmas etc. surgem - como as sementeiras da criatividade cultural de fato". (TURNER apud CARLSON, 2010, p.34) Crianças que brincam e jogam, que podem habitar experiências de borda, 


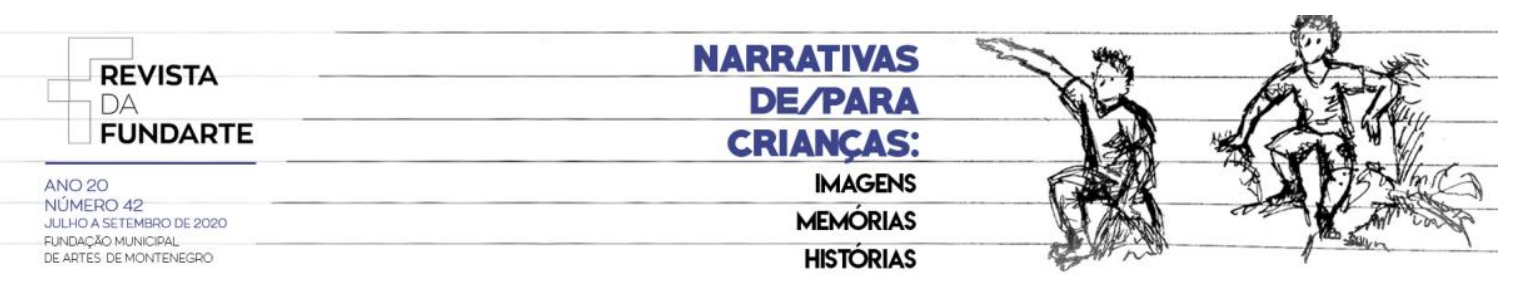

inusitadas, criadas e vividas longe do sistema de regras de trabalho adulto, estão mais próximas da novidade:

Observando os ritos de passagem de Van Gennep, Turner enfatiza não tanto o "estar separado" da performance, mas a sua situação interrelacional, sua função como transição entre dois estados de atividades mais consolidados ou mais convencionais. Essa imagem da performance como uma borda, uma margem, um lugar de negociação tornou-se extremamente importante no pensamento subsequente [...]. (Carlson, 2010, p.30, grifo do autor).

Esses teóricos do "drama social", cujo pensamento emprestou densidade para os estudos antropológicos da performance, são unânimes em afirmar a potência do brincar como lugar de liminaridade - o brincar como "rito limiar" ou liminar: entre papéis, máscaras sociais e ordens e a ruptura da norma estabelecida e aceita. Os adultos - pais, professores, tutores, escritores, produtores culturais - são primordialmente responsáveis pela possibilidade ou não do fenômeno liminar durante anos iniciais das crianças.

Quem, no meio artístico adulto que produz arte para crianças, está disposto a ouvir o que a criança "consumidora" tem a dizer? E quais adultos familiares de crianças artistas mirins que trabalham estão dispostos a rever sua forma de obter renda? Qual a possibilidade de crianças terem autonomia em suas criações, em todas as fases de produção? Quem diante do imediatismo contemporâneo quer correr riscos, incluindo, por exemplo, a desistência da criança cujo adulto responsável assinou contrato e tudo o mais?

\section{Ética e estética do produtor de cultura adulto (em nome, especialmente, da espectadora criança)}

Passados noventa anos da publicação do texto de Benjamin, noutro país e numa circunstância política e social bastante adversa para imaginar ou propor um "teatro infantil proletário", somos bombardeados por dois tipos de produção teatral -uma "para" e outra "com" crianças. Majoritariamente, são propostas adultocentradas e veiculam uma infância dita "universal", cujo mote mais usual é "um tempo de alegria" e de "desenvolvimentismo". 


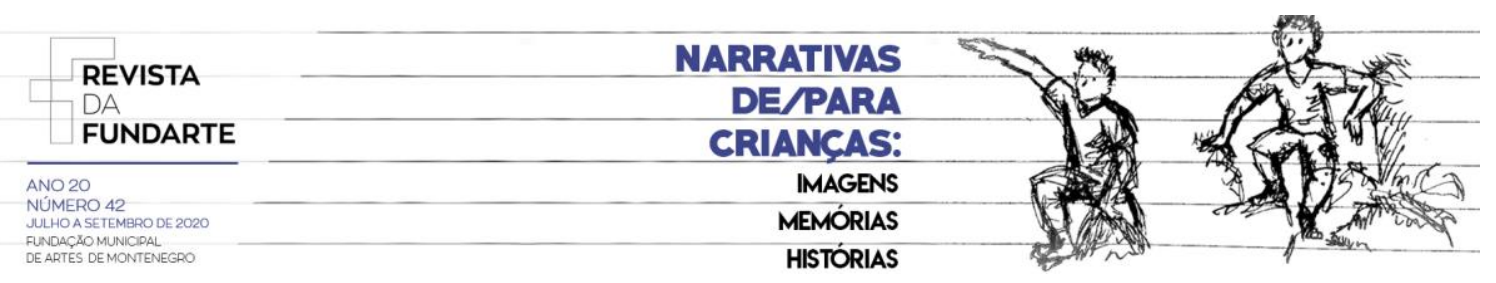

Grosso modo, o que vemos no Brasil é também uma indústria voltada para o consumidor criança, na qual, por exemplo, os quadrinhos invadem a marca de fralda, de maçã, de alface e produtos de papelaria, e os pais adquirem esses produtos com a mesma (pseudo) alegria do marketing ali veiculado... E no campo do ensino do teatro, pouco se fala sobre a potência criativa das crianças mesmas e muito se vê de "mão do gato" em torno de currículos nos quais a arte é uma "linguagem" - a ser aprendida na escola, sempre com base na possibilidade adulta e seu saber alfabetizador naquela área, ainda e sempre em nome de apresentações finais e em datas comemorativas. Na televisão aberta, deparamos com novelas de sucesso envolvendo atores mirins, bem como realities e competições. Na internet, a dinâmica "para" crianças e "com" crianças se repete: milhões de vídeos compartilhados tematizam o cotidiano e o extracotidiano das crianças, e há, como já comentado, o fenômeno dos youtubers mirins.

A convivência entre adultos e crianças na contemporaneidade me parece, assim, cheia de visibilidade e excesso de vigilância; haveria, portanto, escassez de intimidade, silêncio, solitude... características do que se pode nomear "mundo privado", cujo clima e atmosfera seria fundamental preservar. Para que haja silêncio, há que ter desejo de silêncio; susceptibilidade ao silêncio; suportabilidade do silêncio... em caminhos de interioridade. Nas minhas observações fenomenológicas das duplas mãe-e-filho por onde ando, percebo como os adultos não sabem propor momentos de silêncio - nem tampouco experienciar aquilo que Winnicott (1990) denominou por shared solitude ${ }^{8}$ - "solidão compartilhada" (não por acaso meu mestrado transformado em livro apresenta como subtítulo: "teatro da solidão compartilhada"). O espaço vazio (potencialmente cheio de significatividade) dos

\footnotetext{
7 A expressão "mão do gato" foi usada por professores de artes para revelar que o adulto teria interferido diretamente, pondo sua mão na obra da criança ou do jovem: ajudando, modelando, melhorando... seria, do meu ponto de vista, um sinal de insuportabilidade adulta diante da precariedade do trabalho amador.

8 Trata-se de uma noção discutida no ensaio "The capacity to be alone", publicado em 1958 e reunido em livro junto a outros artigos em 1965; grosso modo, significa estar só na presença de alguém (inicialmente o bebê estar só, na presença da mãe ou figura materna) - algo que revela grande maturidade e saúde psíquica. Portanto nada tem a ver com a solidão contemporânea da cultura cibernética ou das grandes cidades.
} 


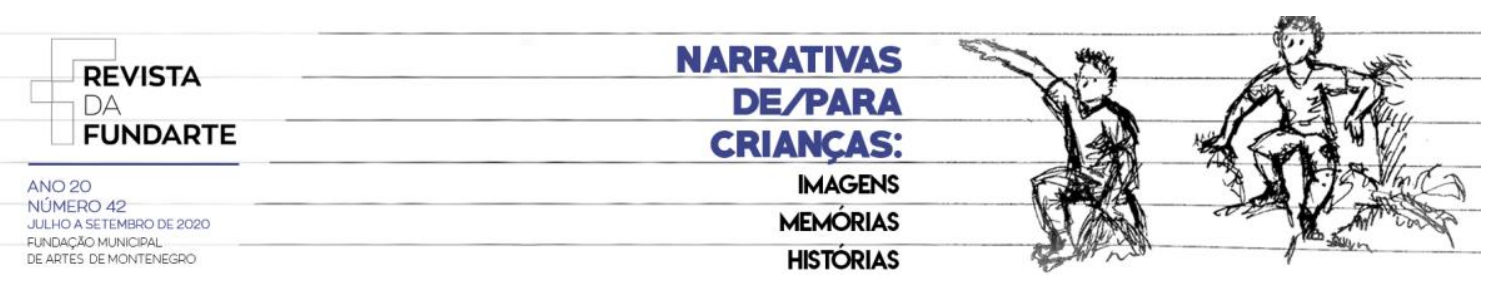

momentos de silêncio compartilhado, hoje, são temidos, e encontram-se usualmente mediados: pelos dispositivos eletrônicos, celulares, tablets, etc, considerados inevitáveis porque naturalizados.

Gostaria de propor a produção cultural feita por adultos que inclua, em boa medida, as crianças, não como atores e atrizes mirins, mas como atores sociais protagonistas, como crianças performers de si, com o outro, no mundo compartilhado, em um horizonte desenhado em diálogo com uma filósofa - assim como Benjamin, também de origem judaica e alemã: Hannah Arendt. No clássico ensaio "A crise na educação" (capítulo do livro Entre o passado e o futuro), Arendt (2014) é enfática acerca do papel adulto diante das crianças: somos responsáveis pelo mundo. As crianças que chegam precisam saber disso...: "um mundo velho, isto é, um mundo pré-existente, construído pelos vivos e pelos mortos" (ARENDT, 2014, p.226). Muitos adultos não querem ser identificados com "o velho"; no entanto no ponto de vista da filósofa, no ato de educar é imprescindível que os adultos representem o velho, a tradição, o que lá já estava, quando as crianças chegaram. Haveriam certas obrigações que "a existência de crianças impõe a toda sociedade humana" (ARENDT, 2014, p.234). E seu diagnóstico, no ensaio publicado nos anos 1960, era de que "a autoridade foi recusada pelos adultos, e isso somente pode significar uma coisa: que os adultos se recusam a assumir responsabilidade pelo mundo ao qual trouxeram as crianças" (ARENDT, 2014, p.240).

O cerne da reflexão de Arendt (2014) atualizada: os adultos estão lavando as suas mãos diante do uso excessivo das novas tecnologias, uma vez que eles mesmos "consultam Dr. Google" acerca da melhor conduta diante dos filhos e consideram interessante, senão essencial, a mediação das coisas do mundo por meio de aplicativos... Falta gesto e palavra - conversa, contação de histórias, comoção com o outro - as coisas de um outro teatro!, cujo início, na vida cultural das crianças, é semeado pelo brincar de faz de conta, no brincar imaginativo compartilhado.

De todo modo o pensamento de Benjamin (1984) parece ainda atual no que diz respeito ao medo que os adultos possam ter da potência transformadora da arte 


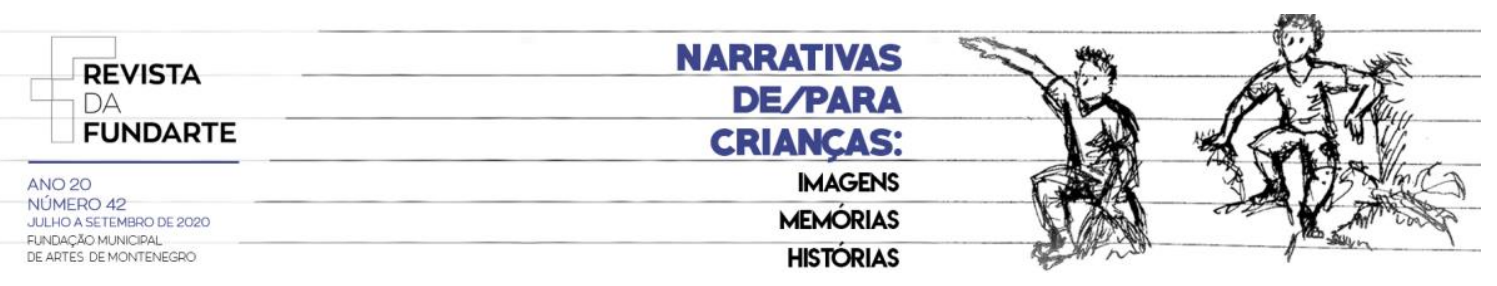

e do teatro criado por crianças e para crianças. A atual retomada mundial dos valores conservadores, nos quais o adulto tutela a criança e o jovem, e no Brasil a demonização do pensamento pedagógico que tematiza o protagonismo infantil, parecem confirmar a hipótese de que há algo "verdadeiramente revolucionário" no "sinal secreto do vindouro, o qual fala pelo gesto infantil" (Benjamin, 1984, p.88).

Vejo similitude entre o que venho denominando "um teatro para todas as idades" e o que Lācis formulou como teatro infantil proletário; levanto ao menos três características importantes: seria algo não comercial, não vendável; seria algo "livre", ou seja, liberto e expressivo, do ponto de vista das crianças; seria algo efêmero, e sem desdobramentos em produtos (um Espetáculo formal) ou subprodutos (livrinho, camiseta, brinde, brinquedo). Proposta latente e pulsante de liminaridade.

\section{Para concluir:}

Desejo, um dia, estar confortável para propor um Programa para um teatro para todas as idades

Na busca por uma contribuição original no diálogo com Benjamin (1984), Lācis (2017), Steinberg e Kincheloe (2001), imagino nesta altura do texto uma utopia de sanidade psíquica, social, convivial - e passível de antiestruturas por parte das crianças, pois poderiam propor e encarnar transformações e desafiar os mundos de vida adultos, revelando sua patetice e mania de disciplina tutelada em teatrinhos, congelados no tempo e emburricadores. Em minha imaginação utópica há espaço para um teatro sem divisão de faixas etárias. Para que ele exista, os adultos precisam agachar-se: ir ao chão, onde a criança está ${ }^{-}$- uma atitude de proximidade; e precisam compreender a potência do teatro, algo vivido no corpo, com enorme carga de discursividade e musicalidade, gesto e palavra: para dizer algo a alguém, em ação.

O caminho é de cuidado com o Outro, espectador daquele momento, daquele acontecimento. Ah, e se são as crianças que performam, o cuidado é saber ouvir e

9 Este o lema de meu site-blog que o leitor poderá encontrar no endereço eletrônico: http://www.agachamento.com 


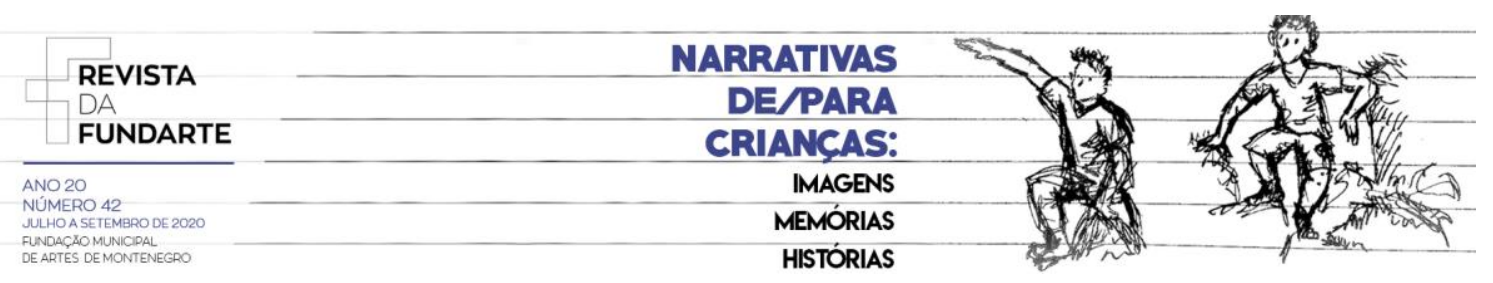

perceber qual território a dramaturgia criada habita. Um teatro feito por crianças para plateias de todas as idades! Um teatro feito por crianças para adultos...

O teatro infantil encenado por adultos no Brasil possui, em sua tradição, um lastro caricaturizado por personagens crianças representadas pelos adultos, muito colorido e muita alegria; esqueceu da tristeza, recalcou o estranhamento, afastou-se da sensação de estrangeiro pela qual todas as crianças invariavelmente passam, com maior e menor intensidade, em diferentes momentos biográficos. Penso que negar a tristeza é desconsiderar a sacralidade do rito do teatro; produzir teatro alegrinho é minimizar a dor e a delícia de ser criança, e de ser recém-chegado no mundo - mundo velho, corrompido, e desejoso de bilheteria, patrocínio e edital: pouca pesquisa e muita concessão para agradar o curador.

Disse Vinícius de Moraes em seu Samba da Benção, composto com Baden Powell, que "fazer samba não é contar piada" - "pra fazer samba é preciso um bocado de tristeza". Parafraseando Vinícius, para fazer teatro inteligente para crianças é preciso dispor da tristeza e da melancolia. Ampliar a cartela de cores.

O contraponto ao teatro alegrinho seria, nesta imaginação espacializada em palavras, um tipo de objeto da cultura repleto de vazios, intimidade, solitude, silêncio e pertença.

Não seria em um grande auditório, é ação sem fumaça de gelo seco, nem música amplificada ou figurinos coloridos.

Aconteceria em uma caixa de sapato ou em um disco de pizza.

As crianças seriam convidadas ao uso do objeto - ao uso criativo das coisas do mundo. Dois ou três adultos, sete ou nove crianças ao redor... Rodinhas de adultos e crianças, mil caixas de sapato, pais e filhos e tios e primos e pessoas de todos os tipos ao redor dos pequenos círculos.

Desafios de ouvir o que não se diz, de imaginar a partir de elementos sutis... Água, terra, fogo e ar como menção a "de onde vem o baião". Brasilidade. E conversa com outras culturas. Delicadeza, muita delicadeza, para falar de nascimento, vida e morte. Liberdade de ir e vir (não precisa ficar na poltrona de veludo!) (nem na cadeira de plástico). 


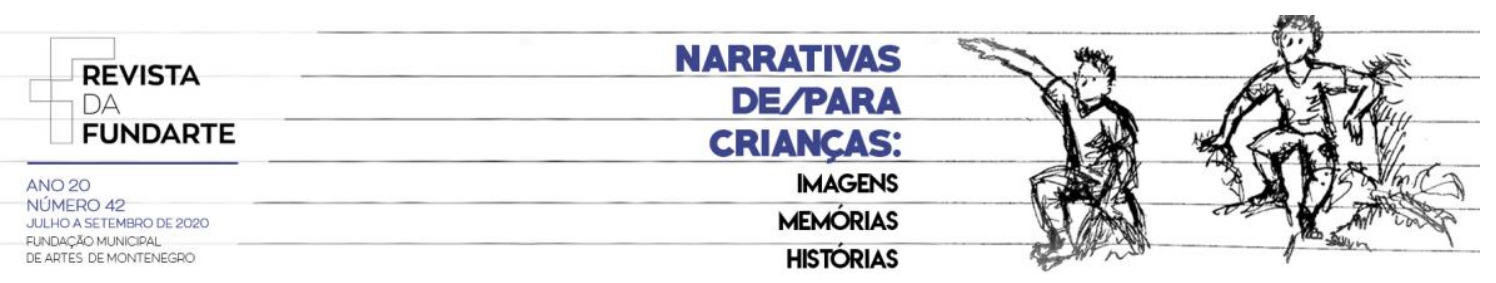

Palavras que emolduram um esboço, um rabisco ainda tímido, para um "programa para o teatro para todas as idades". Não polarizaremos o teatro proletário versus o teatro burguês, mas antes, o teatro engessado em uma infância estereotipada e atemporal versus o teatro como convívio e ato performativo, no tempo do aqui-agora. É nessa chave que ensino práticas e teorias na Licenciatura em Teatro da Universidade Federal de Minas Gerais desde 2012; naquela chave me encantei, na juventude, pela estética do grupo teatral Ventoforte (década de 1980), e escrevi cinco livros ao longo de anos (entre 1994 e 2018); mantenho também um site-blog que comenta de modo reflexivo arte, fenomenologia e infância. A timidez da proposta se dá por habitar uma espécie de contramão ao desenvolvimentismo como leitura da infância e à arte como mercadoria, campos nos quais as crianças encontram dois papéis: a de trabalhadora na indústria cultural voltada a elas mesmas, e a de consumidora: de espetáculos, roupas, canções, xampus, tiaras e chapéus, comidas, vitaminas, adesivos, cadernos, meias e sapatos, camisetas, brinquedos, dispositivos eletrônicos e seus aditivos...

O ideal utópico aqui esboçado implicaria em superar algumas díades: fim das polarizações entre os modelos de infância, um salto para a verdadeira pluralidade de infâncias, com foco nos modos de ser e estar das crianças e em conexão com um código de ética adulto importante.

O papel social e antiestrutural de criador seria a terceira via, um por vir: tempo em que os âmbitos artístico-existenciais poderão ser apropriados, corporeificados e performados por todos, em um espaço potencial aberto para a liberdade, o jogo, as relações, o rito e a liminaridade.

Penso que o campo da indústria cultural tradicional voltada à infância não permitiria, hoje, que essa propositiva se alastrasse, ganhasse força e densidade; a proposta implica em um tipo de saúde psíquica dos adultos, inexistente, e outro tipo de organização produtiva... longe do dinheiro e perto da criança mesma. Embora "a criança mesma" seja, obviamente, também um construto moldado social e historicamente, o direito de ser o que se é na infância implicaria, sempre, numa atitude adulta frente à precariedade, ao inusitado, ao efêmero, ao sinal - diria 


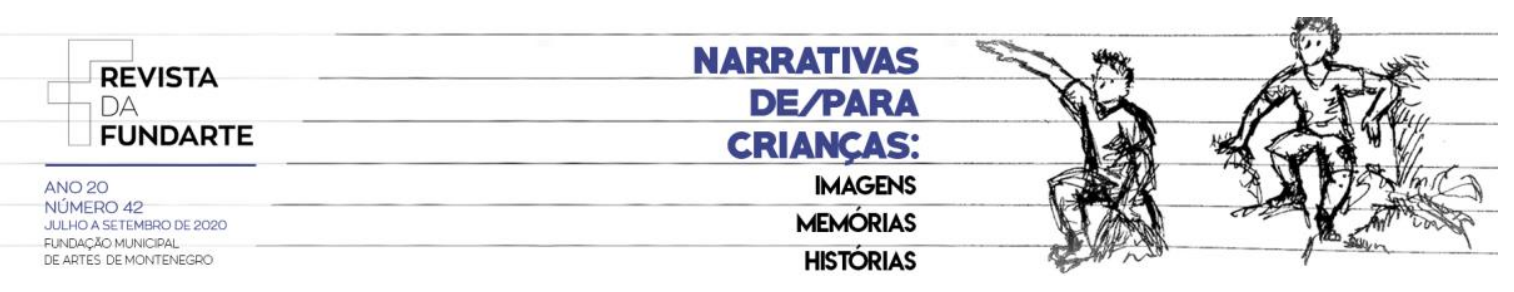

Benjamin (2014) - daquilo que o gesto infantil anuncia diante do adulto fragilizado (ou seria amedrontado?) pela possibilidade de questionamento e transformação.

\section{Referências:}

ARENDT, H. A crise na educação. In: Entre o passado e o futuro. São Paulo: Editora Perspectiva, 2014.

BENJAMIN, W. Programa de um teatro infantil proletário. In: Reflexões: a criança, o brinquedo, a educação. São Paulo: Summus Editorial, 1984.

CARLSON, M. Performance / Uma introdução. Belo Horizonte: Editora da UFMG, 2010.

DUBATTI, J. Teatro, convívio e tecnovívio. In: Da cena contemporânea. Orgs. BIÃO, A. J. de C.; CARREIRA, A. L. N., TORRES NETO, W. L. Porto Alegre: ABRACE, 2012.

KINCHELOE, J.; STEINBERG, S. Orgs. Cultura infantil / A construção corporativa da infância. Rio de Janeiro: Civilização Brasileira, 2001.

LĀCIS, A. Signals from Another World: Proletarian Theater as a Site for Education/ Texts by Asja Lācis and Walter Benjamin, with na introduction by Andris Brinkmanis, 2017.Disponível em: https://www.documenta14.de/en/artists/21976/anna-asja-Lācis Acesso em: 14 mar. 2019.

MACHADO, M. M. A criança é performer. Educação \& Realidade. 35(2), 115-137. maio/ago 2010.2 Disponível em: https://seer.ufrgs.br/educacaoerealidade/article/view/11444. Acesso em: 30 mar. 2019.

MACHADO, M. M. Guerra de maçãs e seus desdobramentos: a escola como paisagem performativa. Cadernos Cedes. V.37, n.101, p.65-82, jan-abr. Campinas, 2017. Disponível em: http://dx.doi.org/10.1590/cc0101-32622017168669. Acesso em: 30 mar. 2019.

MERLEAU-PONTY,M. Psicologia e Pedagogia da criança São Paulo: Martins Fontes, 2006.

STEINBERG, S. Contextualizing Corporate Kids: Kinderculture as Cultural Pedagogy. Comunication \& Social Change, 2(1), 31-57. doi: 10.4471/csc.2014.07 


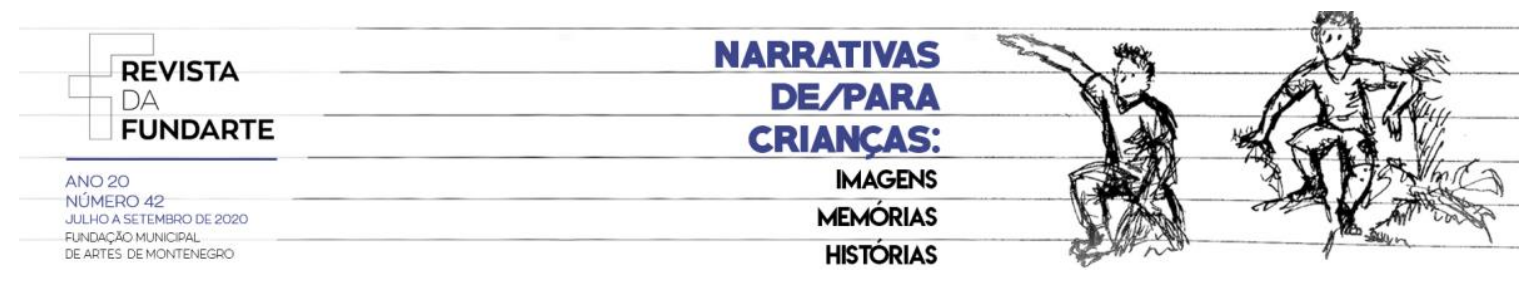

Disponível

em:

https://www.hipatiapress.com/hpjournals/index.php/csc/article/view/1281

Acesso em: 30 mar. 2019.

WINNICOTT, D. W. The capacity to be alone. In: The maturational processes and the facilitating environment. London: Karnac Books, 1990.

MACHADO, Marina Marcondes. Vida ou morte para o teatro infantil? Contrapontos. Revista da FUNDARTE. Montenegro, p.01-20, ano 20, o 42, julho/setembro de 2020.

Disponível em: http://.seer.fundarte.rs.gov.br/index.php/RevistadaFundarte/index> 30 de setembro de 2020 